\title{
Development and Characterization of Colon-targeting 5-Fluorouracil Multiparticulate Beads
}

\author{
M. K. SARANGI ${ }^{1 *}$, M. E. BHANOJI RAO ${ }^{2,3}$, VERSHA PARCHA ${ }^{4}$ AND A. UPADHYAY \\ Sardar Bhagwan Singh Postgraduate Institute of Biomedical Sciences and Research, Balawala, Dehradun-248 008, \\ ${ }^{1}$ Bijupatnaik University of Technology, Odisha-769 004, ${ }^{2}$ Roland Institute of Pharmaceutical Sciences, Berhampur, Odisha-760 \\ $010,{ }^{3}$ Calcutta Institute of Pharmaceutical Technology \& Allied Health Sciences, Howrah-711 $316,{ }^{4}$ Dolphin (PG) Institute of \\ Biomedical \& Natural Sciences, Dehradun, Uttarakhand-248 007, India
}

\section{Sarangi et al.: Colon Targeting Microparticulate System}

This investigation is related to the development and optimization of multiparticulate beads of fenugreek seed mucilage-sodium alginate containing 5-flurouracil through ionotropic gelation technique using $3^{2}$ full factorial design generated with Design-Expert ${ }^{\circledR}$ Version11 software. The beads were developed using $\mathrm{CaCl}_{2}$ as the crosslinking agent. The effect of ratio of fenugreek seed mucilage and sodium alginate blend and concentration of $\mathrm{CaCl}_{2}$ on the drug encapsulation efficiency, bead size and percent cumulative drug release in $6 \mathrm{~h}$ was optimized by $3^{2}$ factorial design. The beads were also characterized using field emission scanning electron microscopy, Fourier-transform infrared spectroscopy and thermal analysis. The percent drug encapsulation efficiency of all these beads was within the range of 43.91 to $85.39 \%$ with an in vitro drug release of 33.92 to $39.23 \%$ in $6 \mathrm{~h}$. The optimized batches of beads were coated with Eudragit $\mathrm{S} 100(5,10$ and $15 \% \mathrm{w} / \mathrm{v})$ to facilitate colon targeting in a prominent way. The in vitro drug release from the coated beads (P3) in various colonic fluids followed zero-order pattern with erosion mechanism in $18 \mathrm{~h}$. The average size of these beads was within the range of 895 to $1021 \mu \mathrm{m}$. The optimized fenugreek seed mucilage-alginate beads containing 5-flurouracil showed significant drug permeability over a prolonged period in an ex vivo permeability study through goat colon. The results indicated successful colon targeting of 5-flurouracil multiparticulate beads developed using polymeric blends containing sodium alginate and fenugreek seed mucilage in an appropriate ratio.

Key words: Fenugreek seed mucilage, sodium alginate, 5-fluorouracil, inotropic gelation, colon targeting

Drugs, those are specifically targeted in the colonic area are highly significant in the treatment of several diseases like ulcerative colitis, Crohn's disease, colorectal cancer and amoebiasis. In addition to the above, the colon-targeted drug delivery systems (CTDDS) posses a high impact in the development of oral delivery of therapeutic peptides and proteins, which are found to be unstable in the upper parts of the gastrointestinal tract. It has been observed that the colonic area is found to be having low intensity along with low diversity of several enzymatic activities in comparison to the stomach and small intestine ${ }^{[1]}$. Several approaches have been developed for targeting the drug release into the colonic $\operatorname{area}^{[2]}$. Polysaccharides like inulin, chitosan, pectin, and guar gum have already been proven their impact in colon-specific drug delivery ${ }^{[3-6]}$. The polysaccharides remain unaffected in the virulent environment of the stomach as well as small intestine and get degraded

*Address for correspondence E-mail: manojsarangi2007@rediffmail.com

May-June 2020 by polysaccharidases on arrival in the colonic area ${ }^{[7]}$. $\mathrm{pH}$-sensitive polymers dissolved at or above $\mathrm{pH} 7.0$, are mostly used for colon targeting. However, as per Ashford et al. such type of polymers are unsuitable for developing CTDDS because of their low site specificity ${ }^{[8]}$. Thus the delayed arrival at the ileocecal junction and quick transit indicates that targeting colon with a single unit may not be a suitable approach for developing a colon-targeted drug delivery system. Over the past few decades, a maximum focus has been intensified for developing hydrogel beads from polysaccharides through ionotropic gelation technique,

This is an open access article distributed under the terms of the Creative Commons Attribution-NonCommercial-ShareAlike 3.0 License, which allows others to remix, tweak, and build upon the work non-commercially, as long as the author is credited and the new creations are licensed under the identical terms

Accepted 18 April 2020

Revised 20 March 2020

Received 04 December 2019 Indian J Pharm Sci 2020;82(3):435-448 
which are considered to be useful as the potential carriers in controlling the drug delivery ${ }^{[9,10]}$. Lack of site specificity is one of the major reasons for the drug in reaching the target site in therapeutic concentrations in colorectal cancer. In order to compensate the lack of site specificity, an increase in the dose size is usually preferred which leads to various toxicities. Researchers have proved targeting the drug to the tumor tissues. The localization of the drug at the colon area helps in getting drug released on colonic region leading to the major amount of the drug entering into the colon. Coating of drugs with several polymeric materials such as cellulose derivatives and acrylic polymers can deliver them directly to large bowel ${ }^{[11]}$. However the encapsulation efficiency of the beads through ionotropic gelation technique developed an ecofriendly environment by avoiding the possible toxicity of reagents associated with chemical cross-linking ${ }^{[9]}$.

Sodium alginate (SA), the widely investigated cationic/ anionic natural polysaccharides, due to an unique nature of developing hydrogel beads with the impact of various bi and trivalent metal ions such as $\mathrm{Ba}^{2+}, \mathrm{Ca}^{2+}, \mathrm{Al}^{3+}$, $\mathrm{Zn}^{2+}$ through an ionic interaction with the carboxylic acid groups located on the polymer backbone ${ }^{[12-14]}$. The cross-linked alginates are mostly fragile irrespective of their mucoadhesive property ${ }^{[15-17]}$. To develop various cross-linked alginate systems for targeting the sites like colon, the use of other polymer-blend along with alginate is one of the widely accepted approaches ${ }^{[17,18]}$.

Drug encapsulation efficiency and stability of beads can be enhanced by a polymeric blend in comparison to cross-linked alginate hydrogel beads, which are developed through ionotropic gelation technique ${ }^{[17,19,20]}$. Literature review indicated that only a few investigations were carried out for developing mucoadhessive beads of SA in association with natural polymeric blend ${ }^{[21-24]}$. Fenugreek seed mucilage (FSM) was basically isolated from Trigonella foenum-graecum L. seeds known as methi, commonly used for culinary purpose ${ }^{[25]}$. A high percentage of mucilage was obtained from fenugreek seeds. However, FSM is already reported to possess pharmaceutical applications such as mucoadhesive gelling $^{[25]}$, binding ${ }^{[26]}$, disintegration ${ }^{[27]}$ and antidiabetic agent ${ }^{[28]}$. Literature review revealed that the major component of the mucilage is galactomannans, which normally act as a hydrophilic sustaining/binding agent. Galactomannan, a hydrophilic hetero polysaccharide from FSM commonly contains D-mannopyranose and D-galactopyranose residues with a molar ratio of 1.2:1.0. The key chain of this galactomannan comprises of b-(1,4)-linked D-mannopyranose residues, in which $83.3 \%$ is substituted at C-6 with a single residue of a-(1,6)-D-galactopyranose. Galactomannan has a molecular weight of $3.23 \times 10^{5} \mathrm{~g} / \mathrm{mol}$ and an intrinsic water viscosity of $235 \mathrm{ml} / \mathrm{g}$. Fenugreek gum (seed endosperm) contains $73.6 \%$ galactomannan. The viscosity of fenugreek gum at $1 \%$ concentration was found to be 286 pa-s $\left(30^{\circ}, 170 / \mathrm{s}\right)$. The viscosity of the solutions decreased sharply as the rate of shear increased and decreased as the temperature of the fully hydrated gum solution was gradually raised from 30 to $90^{\circ}$. Fenugreek gum is an efficient thickening agent and is widely used as a matrixing agent in drug delivery systems ${ }^{[29]}$. The sugar moieties identified in the component were 2,3,4,6-tetra-O-methyl-D-galactose, 2,3,6-tri-O-methyl-D-mannose and 2,3-di-O-methylD-mannose, respectively ${ }^{[30]}$.

5-Fluorouracil (5-FU), an antimetabolite commonly used against colorectal cancer. Cancer chemotherapy in a conventional way is very least impactful against colorectal cancer, as the drug molecule does not available on the target site at a desired therapeutic concentration. In contrast, 5-FU causes severe systemic toxicity, as well as cytotoxicity when administered intravenously ${ }^{[31]}$. On oral administration, it gets rapid renal clearance with a half-life of 8-20 min. However the drug possesses poor absorption, variable bioavailability as well as unusual toxicity in the nontargeted sites. Thus the above nature can be overcome with entrapment/encapsulation ${ }^{[32]}$. Delivering 5-FU directly into the colon leads to reduction in systemic side effects, resulting in an effective and safe therapy with higher tumour diffusivity ${ }^{[33]}$. Thus the current research was designed to achieve a site specific, sustained release using biodegradable polymeric blends of SA and FSM. It is also aimed to focus equal emphasis on testing the sustaining efficiency towards drug release from the polymer blends in colonic condition by developing microbeads especially with FSM.

Multiparticulate beads of 5-FU were formulated using FSM and SA in different ratios using $\mathrm{CaCl}_{2}$ as a crosslinking agent. Thus the multiparticulate polymer beads on ultimate contact with the colonic mucosa should have increased retentivity of the formulation to prolong the liberation of encapsulated drug at the site of absorption in a controlled way to exaggerate the therapeutic potential. The composition of polymerblend on the nature of SA-FSM beads containing 5-FU relating to encapsulation efficiency of drugs along with their release was investigated by computer-based 
optimization technique using with $3^{2}$ full factorial design (response surface methodology). The main rationale behind using these types of polymers (Eudragit S100) is their ability to prevent drug degradation in the gastric environment and their ability to release the drug after entering into the distal ileum. So the main objective is to develop multiparticulate beads of 5-FU with different polymer ratios using ionic gelation technique. Eudragit S100 polymer was used which can provide enteric coating thereby protecting 5-FU in acidic environment in the stomach and releasing it in colon.

\section{MATERIALS AND METHODS}

5-FU was obtained as a gift sample from Yarrow Chem. Pvt. Ltd., Mumbai, India. Fenugreek seed was purchased from the local market of Dehradun, Uttarakhand, India. $\mathrm{SA}$ (viscosity $1 \% \mathrm{w} / \mathrm{v}, 5.5 \pm 2 \mathrm{cps}$ at $25^{\circ}$; D-mannuronate to L-glucoronate ratio, $\mathrm{M} / \mathrm{G}=0.6$ ) and Eudragit $\mathrm{S} 100$ were purchased from Loba Chemi Pvt. Ltd. Mumbai, India and CDH Pvt. Ltd., Mumbai, India, respectively. All other chemicals and reagents used in the study were of analytical grades.

\section{Extraction of FSM:}

Finely powdered fenugreek seeds $(100 \mathrm{~g})$ were placed in $500 \mathrm{ml}$ double distilled water and heated on a water bath at $80^{\circ}$ for $4 \mathrm{~h}$ under continuous stirring. The thick mass obtained was kept at room temperature for $4 \mathrm{~h}$ and left overnight in a refrigerator. The aqueous mucilage was separated by muslin cloth, precipitated with ethanol and acetone treatment, respectively. FSM precipitates were dried, pulverized and passed through mesh no (\#) 80 to obtain uniform powder ${ }^{[34]}$.

\section{Preparation of micro beads containing 5-FU:}

5-FU containing FSM-SA microbeads were developed using the conventional ionotropic gelation method with a slight modification ${ }^{[35]}$. Weighed quantity of FSM (1, 2 and 3 ratio to SA) in $20 \mathrm{ml}$ distilled water heated at $80^{\circ}$ on water bath for $20 \mathrm{~min}$ with occasional stirring. 5-FU (100 mg) homogenized with an SA aqueous solution $(200 \mathrm{mg} / 10 \mathrm{ml})$ was added to the FSM aqueous dispersion. Resulting drug polymer dispersion was added drop wise into $\mathrm{CaCl}_{2}$ aqueous solution $(5,7.5$ and $10 \% \mathrm{w} / \mathrm{v} ; 60 \mathrm{ml}$ ) and subjected to $40 \mathrm{~min}$ curing time. The beads were washed with distilled water and dried at $40^{\circ}$ in a hot air oven.

\section{Characterization of beads:}

Fourier transform infrared spectroscopy (FTIR) and thermal analysis such as differential thermal analysis
(DTA), thermal gravimetric analysis (TGA) and differential thermogravimetry (DTG) were carried out for 5-FU, SA, FSM, polymeric physical mixtures with 5-FU (drug physical mixture, DPM) and without 5-FU (physical mixture, PM). All the samples were ground into powders, mixed with potassium bromide and compressed into disks at $600 \mathrm{~kg} / \mathrm{cm}^{2}$ to obtain solid samples for FTIR analysis. The spectroscopic data was recorded over a wave number region of 4000 to $400 \mathrm{~cm}^{-1}$. FTIR spectra of 5-FU, SA, FSM, and a physical mixture of drug and polymers $(1: 1: 1)$ and the developed FSM-SA beads were recorded at the Indian Institute of Technology, Roorkee, Uttarakhand, India ${ }^{[36]}$.

\section{Thermal analysis:}

TGA, DTG and DTA measurements were made by using simultaneous DTATGA thermal analyser apparatus. Samples (4-7 mg) of 5-FU, SA, FSM, DPM, PM and the developed FSM-SA beads were weighed on a platinum pan. Measurements were carried out from ambient to $900^{\circ}$ under dynamic nitrogen atmosphere with a flow rate of $30 \mathrm{ml} / \mathrm{min}$ and heating rate of $10^{\circ} / \mathrm{min}^{[37]}$.

\section{Bead size and percent drug entrapment efficiency (\% DEE) measurement:}

To determine average bead size, 100 dried beads of each batch were measured on an optical microscope. Percent DEE of beads was quantified in $0.1 \mathrm{~N} \mathrm{HCl}(\mathrm{pH} 1.2)$ using UV/Vis spectrophotometer (UV-1800, Shimadzu, Japan) at $\lambda_{\max } 266 \mathrm{~nm}(\mathrm{n}=3)$ and was calculated using the following Eqn., \% DEE = actual drug content/ theoretical drug content $\times 100$.

\section{Formulation optimization:}

Factorial design in contrast to conventional optimization methods, yields highest amount of information in lowest possible number of trials and simultaneously examines the effect of different variables on the responses and interaction thereof ${ }^{[38,39]} .3^{2}$ full factorial design using Design Expert version 11 software (Stat-Ease, USA) was used for formulation optimization (F1-F9). Based upon two independent variables, $\mathrm{X}_{1}$ (specific ratios of polymers; FSM:SA) and $\mathrm{X}_{2}$ (crosslinking agent; $\mathrm{CaCl}_{2}$ ) at three levels, low $(-1)$, medium $(0)$ and high $(+1)$; $\%$ DEE, bead size $(\mu \mathrm{m})$ and percent drug released in $6 \mathrm{~h}\left(\mathrm{Q}_{6} \%\right)$ were evaluated as dependent variables ${ }^{[40]}$. The response was measured for each run and factorial designs models including linear and quadratic model was fitted by carrying out multiple regression analysis and F-statistics to identify statistically significant 
terms ${ }^{[41]}$. For optimization, the effects of independent variables upon the responses were analysed using quadratic mathematical model as given below ${ }^{[42,43]}$. $\mathrm{Y}=\mathrm{b}_{0}+\mathrm{b}_{1} \mathrm{X}_{1}+\mathrm{b}_{2} \mathrm{X}_{2}+\mathrm{b}_{3} \mathrm{X}_{1} \mathrm{X}_{2}+\mathrm{b}_{4} \mathrm{X}_{11}+\mathrm{b}_{5} \mathrm{X}_{22}$, where, $\mathrm{Y}$ is the response, $b_{0}$ is the intercept and $b_{1}, b_{2}, b_{3}, b_{4}, b_{5}$ are regression coefficients. $X_{1}$ and $X_{2}$ are individual effects, $X_{11}$ and $X_{22}$ are quadratic effects, $X_{1} X_{2}$ is the interaction effect.

\section{Coating of beads (F0):}

Anionic $\mathrm{pH}$-sensitive methacrylic acid and methyl methacrylate copolymer, Eudragit S100 (ES100) was used to promote upper GI stability of the beads. The optimized batch (F0) was coated with ES100 by emulsion solvent evaporation technique using $5 \%$ $\left(\mathrm{P}_{1}\right), 10 \%\left(\mathrm{P}_{2}\right)$ and $15 \%\left(\mathrm{P}_{3}\right) \mathrm{w} / \mathrm{v}$ in acetone-ethanol $(2: 1)^{[44,45]}$. Coated microbeads were dried for $2 \mathrm{~h}$ at $40^{\circ}$. Surface morphology of optimized uncoated (F0) and coated $\left(\mathrm{P}_{3}\right)$ beads was examined by field emissionSEM (FESEM). Randomly selected beads were placed on double-sided copper conductive tape (NEM Nisshin EM Co. Ltd.) fixed on aluminium stubs. The beads were then sputter-coated with a thin layer of gold in a vacuum for $45 \mathrm{~s}$ at $20 \mathrm{~mA}$ using a coating unit (Cressington 108 auto sputter coater, UK) to make it electrically conductive and was analysed at $5 \mathrm{kV}$ at Indian Institute of Technology, Roorkee, Uttarakhand, India ${ }^{[46]}$.

\section{In vitro drug release profile, release kinetics and permeability studies:}

For release profile study, uncoated and coated microbeads of SA (U0 and $\mathrm{C} 0$ ) and SA-FSM (F0, P1, P2 and P3), equivalent to $100 \mathrm{mg}$ of 5-FU, were transferred into the basket and placed into dissolution baths containing $900 \mathrm{ml}$ of simulated gastric fluid ( $\mathrm{pH} 1.2$ for $0-2 \mathrm{~h}$ ), simulated intestinal fluid (pH 6.8 for 2-6 h; $\mathrm{pH} 7.4$ for 6-18 h) in an USP type I apparatus (Electrolab Dissolution Tester, TDT 08L, Mumbai, India) maintained at $37 \pm 0.5^{\circ}$ and $50 \pm 3 \mathrm{rpm}$. The concentration of 5-FU was determined on a double beam UV/Vis spectrophotometer at $\lambda_{\text {max }}$ $266 \mathrm{~nm}$ against a standard calibration plot with a concentration range $2-18 \mu \mathrm{g} / \mathrm{ml}$ in simulated dissolution media of $\mathrm{pH} 1.2,6.8$ and 7.4. An ex vivo permeability study using Franz diffusion was conducted for 5-FU and optimized formulations coated $\left(\mathrm{P}_{3}\right)$ and uncoated (F0) beads. Permeability was observed for $18 \mathrm{~h}$ on the excised colonic mucosal membrane at $37^{\circ} \pm 0.5^{\circ}$, at a low speed $(35 \mathrm{rpm})^{[43]}$.
Release kinetics of coated and uncoated beads (F0 and P3) was also studied in simulated biological fluids including fluid thioglycolate media (FTM) containing probiotics, human faeces and goat caecum, under anaerobic conditions ${ }^{[32]}$. Kinetic parameters including zero order, first order, Higuchi's and Korsmeyer-Peppas equations were investigated ${ }^{[47,48]}$. Optimized formulations were first exposed to dissolution media ( $\mathrm{pH} \mathrm{1.2,} 2$ h; $\mathrm{pH} \mathrm{6.8,} 4$ h), followed by probiotic culture media containing FTM, $5.0 \% \mathrm{w} / \mathrm{v}$ human faecal slurries, $4.5 \% \mathrm{w} / \mathrm{v}$ of goat caecal content and FTM without microbiota, respectively, maintained at a $\mathrm{pH}$ of $7.4^{[49,50]}$. 5-FU was quantified using UV/Vis spectrophotometer at $266 \mathrm{~nm}$.

\section{Statistical analysis:}

The statistical significance of the differences between two means was evaluated using ANOVA. A value of $p<0.05$ was considered as significant. Statistical optimization was performed with the Design-Expert ${ }^{\circledR}$ Version 11 software (Stat-Ease Inc., USA).

\section{RESULTS AND DISCUSSION}

SA and FSM beads were prepared by dropping the solution of the 5-FU SA-FSM dispersion into calcium chloride solution, where beads were developed because of cross linking of alginate by calcium ions. Preparation of beads by ionotropic gelation is based on the ability of various polysaccharides such as pectin, alginate, chitosan, and gellan to form a gel in the presence of multivalent ions. Beads can therefore be prepared simply by adding, drop wise, a dispersion of polysaccharide and material to be encapsulated into solution of multivalent ions. The contact of droplets with the ions results in instantaneous formation of spherical gel structures containing the material to be encapsulated uniformly dispersed throughout the polysaccharide matrix. SAFSM micro beads were successfully prepared by the ionotropic gelation method. The beads were coated with ES100 by emulsion solvent evaporation technique. The coated beads were found to be of spherical shape. Diameter of beads varied as shown in Table 1 for different formulations. The result indicated that as the amount of polymer (SA and FSM) increased, the size of beads proportionally increased. The permeability study of the drug through goat intestinal membrane shoed a good response.

FTIR spectra were recorded on a Perkin Elmer FTIR spectrum-2 and-summarized in fig. 1. IR spectra of SA showed $1032 \mathrm{~cm}^{-1}$ (C-O-C stretching) attributed 
TABLE 1: $3^{2}$ FACTORIAL DESIGNS WITH MEASURED RESPONSES OF FSM-SA BEADS CONTAINING 5-FU

\begin{tabular}{|c|c|c|c|c|c|}
\hline \multicolumn{6}{|c|}{ A } \\
\hline Batch & $\mathrm{X}_{1}(\mathrm{FSM}: \mathrm{SA})$ & $\mathrm{X}_{2}\left(\mathrm{CaCl}_{2} \%\right)$ & $\%$ DEE & BS $(\mu \mathrm{m})$ & $\% Q_{6}$ \\
\hline $\mathrm{F} 1$ & $1: 1(-1)$ & $5(-1)$ & $43.91 \pm 1.56$ & $895 \pm 1.34$ & $39.23 \pm 1.23$ \\
\hline $\mathrm{F} 2$ & $1: 1(-1)$ & $7.5(0)$ & $46.19 \pm 1.26$ & $911 \pm 1.24$ & $38.42 \pm 1.02$ \\
\hline F3 & $1: 1(-1)$ & $10(+1)$ & $48.46 \pm 1.31$ & $925 \pm 1.34$ & $38.61 \pm 0.98$ \\
\hline $\mathrm{F} 4$ & $2: 1(0)$ & $5(-1)$ & $55.51 \pm 0.85$ & $946 \pm 1.25$ & $37.89 \pm 0.78$ \\
\hline F5 & $2: 1(0)$ & $7.5(0)$ & $65.79 \pm 0.98$ & $963 \pm 1.24$ & $35.07 \pm 1.36$ \\
\hline F6 & $2: 1(0)$ & $10(+1)$ & $74.07 \pm 1.56$ & $978 \pm 0.85$ & $36.26 \pm 2.01$ \\
\hline F7 & $3: 1(+1)$ & $5(-1)$ & $78.11 \pm 1.24$ & $991 \pm 1.45$ & $35.54 \pm 2.15$ \\
\hline F8 & $3: 1(+1)$ & $7.5(0)$ & $85.39 \pm 1.63$ & $1008 \pm 0.97$ & $34.73 \pm 1.32$ \\
\hline F9 & $3: 1(+1)$ & $10(+1)$ & $81.67 \pm 1.89$ & $1021 \pm 1.45$ & $33.92 \pm 1.45$ \\
\hline \multicolumn{6}{|c|}{ B } \\
\hline \multicolumn{6}{|c|}{ F0 (Optimized Formulation) } \\
\hline & X1 (FSM:SA) & $\mathrm{X}_{2}\left(\mathrm{CaCl}_{2} \%\right)$ & \% DEE & BS $(\mu \mathrm{m})$ & $\% Q_{6}$ \\
\hline Predict & \multirow{3}{*}{$3.06: 1$} & \multirow{3}{*}{7.36} & 80.97 & 1003.76 & 36.22 \\
\hline Observ & & & $78.83 \pm 1.89$ & $999.3 \pm 1.29$ & $38.74 \pm 1.65$ \\
\hline$\%$ Error & & & $2.14 \%$ & $4.76 \%$ & $-2.52 \%$ \\
\hline
\end{tabular}

$\%$ Error $=($ predicted value-observed value $) /$ predicted value $\times 100$. Responses were measured in triplicate

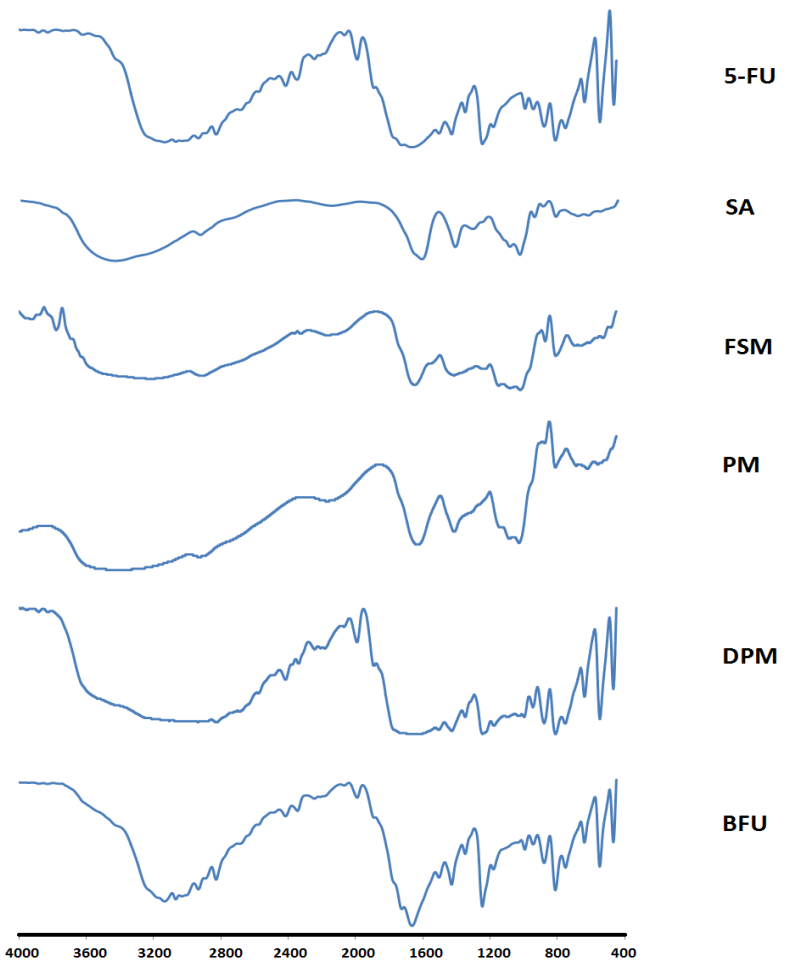

Fig.1 FTIR spectra

5-FU: 5-fluorouracil, SA: sodium alginate, FSM: fenugreek seed mucilage, (PM) SA+FSM polymer mixer, (DPM) 5-FU + SA + FSM drug polymer mixer, BFU: beads of 5-FU

to saccharide structure and bands at 1615 and $1416 \mathrm{~cm}^{-1}$ were of asymmetric and symmetric carboxylate ion stretching ${ }^{[51]}$. FSM spectral lines at 3227,1020 and $1414 \mathrm{~cm}^{-1}$ were of O-H, -C-O stretching and C-O-C linkage, respectively. The peaks observed at 810 and $872 \mathrm{~cm}^{-1}$ correspond to the $-\mathrm{CH}$ oscillations of (b-mannopyranose residues of fenugreek galactomannan) and the absence of peak around $1560 \mathrm{~cm}^{-1}$ for amide confirms the absence of proteins impurity ${ }^{[29]}$. 5-FU has characteristic peaks at 2934, 1666, 1429,1181 and $1348 \mathrm{~cm}^{-1}$. All these characteristic peaks were similar to previous observations reported ${ }^{[32,33]}$. DPM and calcium alginate-FSM beads containing 5-FU (BFU) spectra showed peaks corresponding to all 3 constituents. FTIR spectra of BFU showed peaks at 3068,1990 , and $1664 \mathrm{~cm}^{-1}$, without any significant shifting, indicating the absence of covalent interaction between the 5-FU and used polymers ${ }^{[29,52]}$.

Differences in the thermal decomposition behavior of 5-FU and polymers were clearly observed through Exstar SII TG/DTA 6300 and the thermograms were depicted in fig. 2 and Table 2. The DTA of 5-FU showed a sharp endothermic peak at $279^{\circ}$, which corresponded to the melting point of 5-FU (fig. 2A) ${ }^{[14]}$. Percent weight loss with increasing temperature was almost steady up to $200^{\circ}$ for 5-FU and maximum loss $\left(\mathrm{T}_{\max }\right)$ was observed at $328^{\circ}$ with a rate of $12.57 \% / \mathrm{min}$ at $319^{\circ}$, which could be due to single stage decomposition of 5-FU (fig. 2; Table 2). Whereas, SA showed an exothermic peak at $244^{\circ}$, it exhibited major weight loss up to $300^{\circ}$ with the onset of major decomposition occurred at $200^{\circ}$ $\left(\mathrm{T}_{0}\right.$ ) with the highest rate of $6.63 \% / \mathrm{min}$ at $242^{\circ}$ (fig. 2 ). SA decomposed in 3 steps, where first was attributed to water loss, followed by the formation of a carbonaceous residue and finally $\mathrm{Na}_{2} \mathrm{CO}_{3}{ }^{[53]}$.

FSM underwent strong thermal degradation up to $400^{\circ}$, which could be attributed to 2 stage decomposition events of galactomannan depicted by all other polymers ${ }^{[54-57]}$. First was near $100^{\circ}$, might be attributed to the loss of 

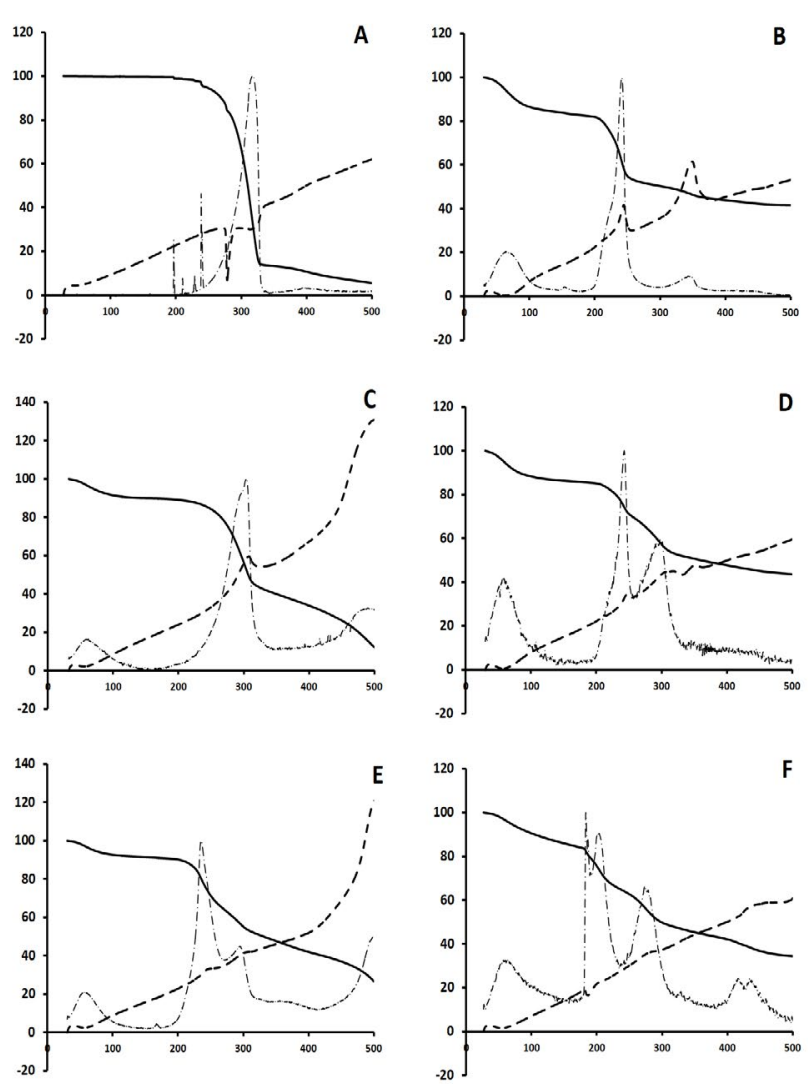

Fig. 2: Thermograms

A- 5-fluorouracil (5-FU), B- sodium alginate (SA), C- fenugreek seed mucilage (FSM), D- polymer mixer (PM, SA+FSM), Edrug polymer mixer (DPM) and F- beads of 5-FU (BFU). (:) \% TG, (:11) DTG \%/MIN, (---) DTA

water associated with hydrophilic functional groups of the polysaccharide chain $\left(\sim 11 \%\right.$ at $\left.200^{\circ}\right)$. The second mass loss event resulted in a weight loss due to polysaccharide thermal decomposition, presenting peaks of the derivate of the weight loss curve (DTG) at $305^{\circ}$ with highest rate of $5.30 \% / \mathrm{min}$ (Table 2). These findings also corroborated to the values reported by Miguel et al. for the galactomannan extracted from Gleditsia triacanthos, Caesalpinia pulcherrima and Adenanthera pavonina, with values of 309.81, 321.73 and $320.62^{\circ}$, respectively ${ }^{[58,59]}$.

However, PM of SA and FSM showed an exothermic peak at $246^{\circ}$ and major weight loss started from $200^{\circ}$ $(14.93 \%)$ up to $400^{\circ}(52.29 \%)$, whereas the rate of decomposition was observed highest $3.20 \% / \mathrm{min}$ at $243^{\circ}$ and $1.87 \% / \mathrm{min}$ at $301^{\circ}$, attributed to the decomposition of SA and FSM, respectively (fig. 2). Moreover, DPM showed an exothermic peak at $246^{\circ}$, contributed by SA with significant decomposition rate of $3.88 \% / \mathrm{min}$ at $235^{\circ}$ and $1.74 \% / \mathrm{min}$ at $296^{\circ}$ (fig. 2). BFU showed a characteristic exothermic peak at $187^{\circ}$ and exhibited relatively slower rate of decomposition of $2.65,2.42$ and $1.75 \% / \mathrm{min}$ at 183,203 and

$274^{\circ}$, respectively, which ranged from $181^{\circ}$ to $400^{\circ}$ (fig. 2). The rate of decomposition of PM and DPM was observed quite slow and steady as compared to that of 5-FU, SA and FSM. This slower degradation of mass in case of PM and DPM and the absence of 5-FU characteristic endothermic decomposition peak in BFU signified better stability of the formulation, which could be due to ionic crosslinking of 5-FU molecule within the PM of polymeric blend and supported the ionic interaction hypothesis of FTIR findings ${ }^{[0,53]}$. All these findings also corroborated with polymer-induced stability to drug molecules in the ionic gelation matrix and the findings were quite satisfactory compared to the data reported by Patel et al. and Nithitanakool et al. ${ }^{[61,62]}$.

Morphological analysis at magnifications of 100 , 1000 and 5000X, respectively, for both coated $\left(\mathrm{P}_{3}\right)$ and uncoated optimized BFU (F0) by FESEM, (FEI Quanta 200F), revealed the impact of ES100 coating on bead surface morphology (fig. 3). ES100, an anionic $\mathrm{pH}$-sensitive copolymers of methacrylic acid and methyl methacrylate and emulsion solvent evaporation technique were used for coating beads. Slow evaporation of solvent resulted in a polymeric coating over microbeads ${ }^{[45]}$. Uncoated beads were circular in shape with wrinkles and cracks along with the fibers of the mucilage, which may be due to partial collapsing of polymeric gel networks during drying (fig. 3). Polymeric debris was seen on the bead surface, which could be due to the method of preparation of simultaneous gel bead preparation and formation of the polymer-blend matrix ${ }^{[63]}$. However, the ES100coated beads showed smooth texture and lesser cracks (fig. 3). The larger porosity observed in uncoated beads is reduced by ES 100 coating. The quadratic equation for the \% DEE is given as follows, \% DEE (Y1) = $65.68+17.94 \mathrm{X}_{1}+4.11 \mathrm{X}_{2}-1.34 \mathrm{X}_{11}-0.84 \mathrm{X}_{22}+0.25 \mathrm{X}_{12}$.

TABLE 2: PERCENT WEIGHT LOSS OF 5-FU, SA, FSM, PM, DPM AND BFU ON THERMO GRAVIMETRIC ANALYSIS

\begin{tabular}{lcccccc}
\hline $\begin{array}{l}\text { Temperature } \\
\left({ }^{\circ}\right)\end{array}$ & \multicolumn{6}{c}{ \% Weight loss } \\
\hline & 5-FU & SA & FSM & PM & DPM & BFU \\
\hline $0-200$ & 1.08 & 18.16 & 10.90 & 14.91 & 9.86 & 24.44 \\
$201-250$ & 5.55 & 45.13 & 15.75 & 28.84 & 28.59 & 37.28 \\
$251-300$ & 33.26 & 49.66 & 43.59 & 42.70 & 44.81 & 50.21 \\
$301-350$ & 86.69 & 53.63 & 60.02 & 49.26 & 52.29 & 54.66 \\
$351-400$ & 89.29 & 56.10 & 66.09 & 52.27 & 58.03 & 57.85 \\
$401-450$ & 92.28 & 57.72 & 73.78 & 54.86 & 62.97 & 63.20 \\
$451-500$ & 94.47 & 58.44 & 87.79 & 56.34 & 73.31 & 65.59 \\
$\mathrm{~T}_{\max }$ & $328^{\circ}$ & $255^{\circ}$ & $315^{\circ}$ & $316^{\circ}$ & $300^{\circ}$ & $300^{\circ}$ \\
\hline
\end{tabular}



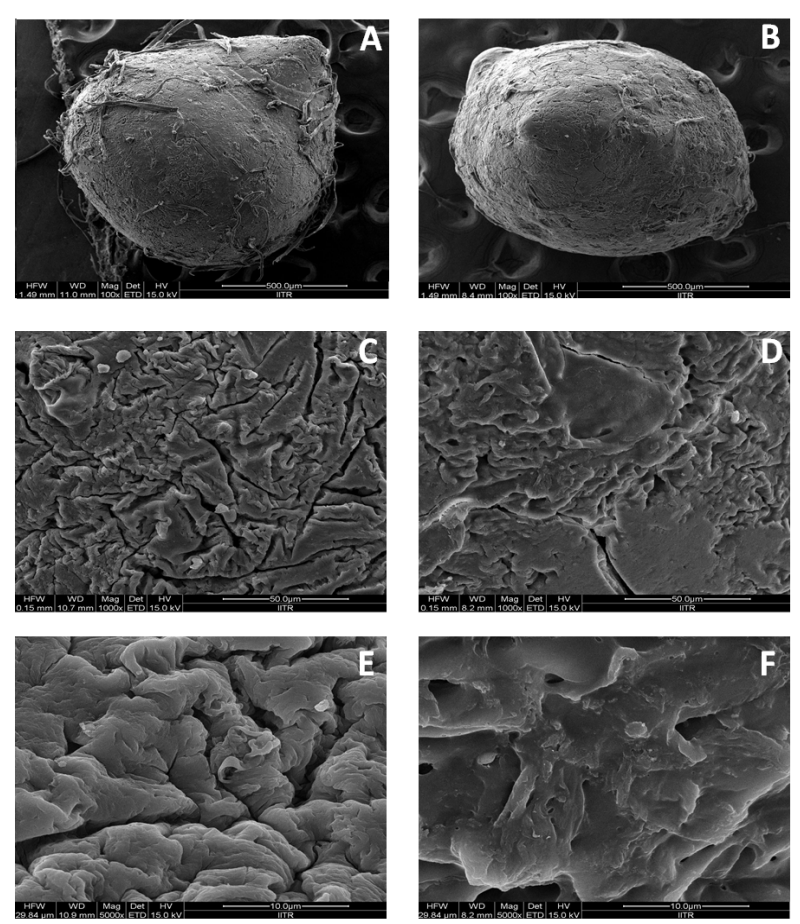

Fig. 3: Field emission-SEM images of 5-FU beads

$A, C$ and E-uncoated; B, D and F-coated beads; $A$ and B-100X, scale bar $500 \mu \mathrm{m}$; $C$ and D-1000X, scale bar $50 \mu \mathrm{m}$; $E$ and F-5000X, scale bar $10 \mu \mathrm{m}$
The contour and surface response plots for $\%$ DEE were displayed in fig. 4 . The DEE (\%) of BFU ranged $43.91 \pm 1.56$ to $85.39 \pm 1.63 \%$ (Table $2 \mathrm{~A}$ ). The regression analysis of DEE (\%) for batches $\mathrm{F}_{1}$ to $\mathrm{F}_{9}$ revealed that the coefficient of variable $X_{1}\left(b_{1}=17.94\right)$ was statistically significant $(\mathrm{p}<0.05)$ and highly dominating $\left(\mathrm{b}_{1}>\mathrm{b}_{2}\right)$ in comparison to $\mathrm{X}_{2}\left(\mathrm{~b}_{2}=4.11\right)$. Hence, the polymeric ratio of (FSM:SA) $\left(\mathrm{X}_{1}\right)$ is playing a key role towards increasing the DEE of the formulation as compared to the concentration of $\mathrm{CaCl}_{2}\left(\%, \mathrm{w} / \mathrm{v}, \mathrm{X}_{2}\right.$, Table 3). The interaction between $\mathrm{X}_{1}$ and $\mathrm{X}_{2}$ showed positive impact on viscosity $\left(b_{12}=0.25\right)$. ANOVA for DEE was carried out. The model F-value of 52.80 implied that the model was significant. Values of $\mathrm{p}$ less than 0.05 indicated that the model terms were significant. However, 5-FU encapsulation of the developed beads was increased with increasing amount of both FSM and SA, which might be due to the increased viscosity of polymeric blend, which increased formation of a dense polymer network thus preventing the drug from leaving the droplet during crosslinking process. It was also resulted from the ionic cross-linking by increased concentrations of calcium ions to anionic sites of alginate molecules ${ }^{[64]}$. The high entrapment might also
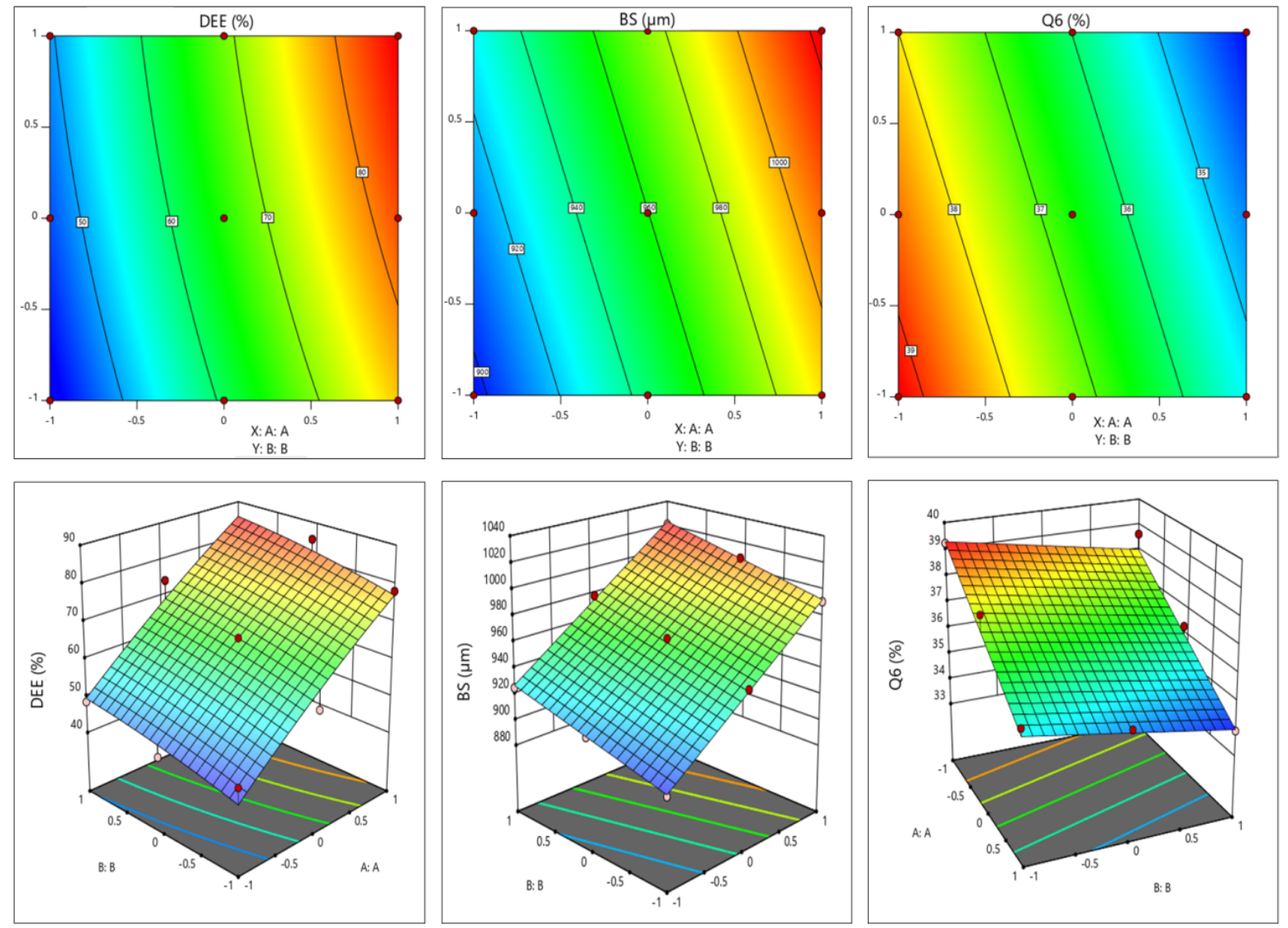

Fig. 4: 3D-Response surface and contour plots for \% DEE and BS

$\%$ DEE is drug entrapment efficiency, BS is bead size in $\mu \mathrm{m}$ and $\% Q_{6}$ is drug release in $6 \mathrm{~h}$ 
TABLE 3. SUMMARY OF RESULTS OF REGRESSION ANALYSIS OF FULL AND REDUCED MODEL

\begin{tabular}{lcccccc}
\hline \multirow{2}{*}{ Response } & \multicolumn{2}{c}{$\%$ DEE } & \multicolumn{2}{c}{ BS $(\mu \mathrm{m})$} & \multicolumn{2}{c}{$\%_{6}$} \\
\cline { 2 - 7 } & $\mathrm{FM}$ & $\mathrm{RM}$ & $\mathrm{FM}$ & $\mathrm{RM}$ & $\mathrm{FM}$ & $\mathrm{RM}$ \\
\hline b0 & 65.68 & 64.23 & 963.22 & 959.78 & 35.86 & 36.63 \\
$b 1$ & 17.94 & 17.94 & 48.17 & 48.17 & -2.01 & -2.01 \\
$b 2$ & 4.11 & 4.11 & 15.33 & 15.33 & -0.644 & -0.644 \\
$b 11$ & -1.34 & - & -3.83 & - & 0.33 & - \\
$b 22$ & -0.84 & - & -1.33 & - & 0.83 & - \\
$b 12$ & 0.25 & - & -5.06 & - & -0.25 & - \\
P value & 0.0377 & 0.0002 & 0.0001 & 0.0001 & 0.0370 & 0.0014 \\
F Value & 11.09 & 52.80 & 5185.27 & 1324.58 & 11.25 & 23.70 \\
Df & 5 & 2 & 5 & 2 & 5 & 2 \\
& \multicolumn{7}{c}{ Quadratic Model (FM) } & & Linear model (RM) & \\
\hline \% DEE & Obtained & Predicted & Adjusted & Obtained & Predicted & Adjusted \\
BS $(\mu \mathrm{m})$ & 0.9487 & 0.3742 & 0.8631 & 0.9462 & 0.8737 & 0.9283 \\
$\%$ Q & 0.9999 & 0.9986 & 0.9997 & 0.9977 & 0.9950 & 0.9970 \\
\hline
\end{tabular}

Correlation coefficient $\left(\mathrm{R}^{2}\right)$ value of FM and RM. FM-Full model, RM- reduced model

be due to inclusion of drug into hollow hilum of the $\mathrm{FSM}^{[65]}$. The contour and surface response plot for DEE were displayed in fig. 4. Response surface graphs were generated which represent simultaneous effect of one variable on response parameters by taking another variable at a constant level. The $\mathrm{P}$ value $(5 \%$ level) and the value of correlation coefficient $\left(\mathrm{R}^{2}\right)$ obtained for effect on DEE was 0.0002 and 0.9487 indicating a good fit of the model. The counter plot for the effect on DEE (fig. 4) shows that the green zone having the specified point is the zone where best result would be obtained with the polymeric ratio at (3.06:1, FSM:SA) and the concentration of crosslinking agent $\left(\mathrm{CaCl}_{2}\right)$ at $7.36 \%$. Moreover, the 3D response surface plot (fig. 4) suggested that as the concentrations of polymer ratio increases up to certain extent, a good entrapment efficiency of 5-FU was observed. Similarly an increased concentration of crosslinking agent led to a better DEE. Both the combined effect of polymeric ratio and concentration of crosslinking agent lead to a positive impact on $\mathrm{DEE}^{[66]}$. The quadratic equation for $\mathrm{BS}$ is given as follows, $\mathrm{BS}(\mathrm{Y} 2)=963.22+48.17 \mathrm{X}_{1}+15.33 \mathrm{X}_{2}$ $3.83 \mathrm{X}_{11}-1.33 \mathrm{X}_{22}-5.06 \mathrm{X}_{12}$.

Average size of these formulated dried beads containing 5-FU ranged from $895 \pm 1.34$ to $1021 \pm 1.45 \mu \mathrm{m}$ (Table 1A). The regression analysis of the bead size data in batches F1 to F9 using reduced model, revealed that the impact of the independent variable $\mathrm{X} 2(\mathrm{~b} 2=15.33)$ was insignificant in comparison to $\mathrm{X} 1 \quad(\mathrm{~b} 1=48.17$, Table 3). Hence, a significant change in bead size must be attributed to a change in concentration of FSM:SA. The interaction between X1 and X2 showed the negative impact on viscosity $(\mathrm{b} 12=-5.06)$. The quadratic values X11 and X22 possess negative impact, $(\mathrm{b} 11=-3.83, \mathrm{~b} 22=-1.33)$ respectively on bead size (Table 3A). ANOVA for bead size was carried out. The Model F-value of 1324.58 implies the model is significant. Values of $\mathrm{p}$ less than 0.05 indicated that model terms were significant. From the results obtained through the experiment, it was observed that with the increase in concentration of FSM, the size of the beads was increased. This could be due to an increase in viscosity of the polymeric mixture, which in turn increased the bead size, additionally accumulating polymeric mucilage along with SA under the influence of chemical crosslinking via calcium chloride as well as with interactions such as $\mathrm{H}$-bonding ${ }^{[65]}$. The contour and surface response plot for bead size were displayed in fig. 4. The $\mathrm{P}$ value (5\% level) and the value of correlation coefficient (R2) obtained for effect on bead size was 0.0001 and 0.9999 indicating a good fit of the model. The counter plot for bead size (fig. 4) shows that the green zone having centre spot is the zone where best results would be obtained with the polymeric ratio at (3.06:1, FSM:SA) and the concentration of crosslinking agent $(\mathrm{CaCl} 2)$ at $7.36 \%$. The $3 \mathrm{D}$ response surface plot (fig. 4) suggested that as the concentrations of polymer ratio increases up to certain extent, it leads to increase in the bead size. The increase in concentration of crosslinking agent up to certain extent leads to an increase in bead size. It can be concluded that the polymeric ratio (X1) has positive effect on bead size. While concentration of crosslinking agent (X2) did not show much effect on it. Both the combined effect of concentrations of polymer ratio and crosslinking agent leads to positive effect on bead size ${ }^{[66]}$. The quadratic equation for BS is given as follows, \% Q6 (Y3) = 
35.86-2.01X1-0.644X2 +0.33X11+0.83X22-0.25X12. Percent drug released in $6 \mathrm{~h}(\% \mathrm{Q} 6)$ data for batches F1 to F9 was analysed and summarized in Table 1 . The average percentage of drug release in $6 \mathrm{~h}(\% \mathrm{Q} 6)$ for the developed beads containing 5-FU lie within the range of $33.92 \pm 1.45$ to $39.23 \pm 1.23 \%$ (Table $2 \mathrm{~A}$ ). The coefficient of variable $\mathrm{X} 1$ was $(\mathrm{b} 1=-2.01)$ and that of $\mathrm{X} 2$ was $(\mathrm{b} 2=-0.64)$ for Q6. Both $\mathrm{b} 1$ and $\mathrm{b} 2$ showed negative effect on drug release at $6 \mathrm{~h}$. The coefficient of $\mathrm{X} 11$ was $(\mathrm{b} 11=0.33)$ and that of X22 was $(\mathrm{b} 22=0.83)$ which indicated their positive impact on drug release (Table 3A). The coefficient of b12 was $(-0.25)$. Thus the data revealed that the quadratic response of $\mathrm{X} 2$ was greater than that of $\mathrm{X} 1$ towards drug release. The drug release at a lower polymeric ratio (X1, FSM:SA) at a variable $\mathrm{pH}$ condition of the respective media $(\mathrm{pH}$ 1.2 and 6.8) with an elevated concentration of $\mathrm{CaCl} 2$ (5-10\%) leads to a comparatively increased \% Q, which was further reduced. This could be due to the effect of increased polymer concentration (X1) on the retention of drug as compared to $\mathrm{CaCl} 2$ concentration (X2). This can be related to the formation of densely cross-linked polymeric layer on the surface of droplets which resists to $\mathrm{Ca}++$ diffusion into the beads' core, leading to the formation of beads with unreacted or partially reacted core with smaller resistance to drug release. These findings agree with those reported by Tavakol et al. ${ }^{[67]}$. ANOVA for percent cumulative drug release for $6 \mathrm{~h}$ was carried out. The model F-value of 53.70 implies the model is significant. Values of $\mathrm{p}$ less than 0.05 indicated that the model terms were significant. Increasing $\%$ DEE, bead size and decreased \% Q6 release should be attributed to the increased viscosity of the FSM and SA polymer-blend and greater degree of cross linking, which in turn increased the droplet size as evident from F8 and F9 (Table 1A). The R2 values (obtained, predicted and adjusted) for all three responses were depicted in Table 3B. The contour and surface response plot for Q6 \% were displayed in fig. 4. The P value (5\% level) and the value of correlation coefficient (R2) obtained for effect on $\%$ drug release at $6 \mathrm{~h}$ was 0.0014 and 0.9494 indicating a good fit of the model. The counter plot for $\%$ drug release at $6 \mathrm{~h}$ (fig. 4 ) shown that the green zone having centre spot is the zone where best results would be obtained with the polymeric ratio at (3.06:1, FSM:SA) and the concentration of crosslinking agent $\left(\mathrm{CaCl}_{2}\right)$ at $7.36 \%$. The $3 \mathrm{D}$ response surface plot (fig. 4) suggested that as the concentrations of polymer ratio increased up to certain extent, it led to decrease in the $\%$ drug release rate at $6 \mathrm{~h}$. The increase in concentration of crosslinking agent up to certain extent also leads to a decrease in $\%$ drug release rate at $6 \mathrm{~h}$. It can be concluded that the polymeric ratio (X1) has negative effect on $\%$ drug release at $6 \mathrm{~h}$. While concentration of crosslinking agent (X2) also showed negative effect on it. Both the combined effect of concentrations of polymer ratio and crosslinking agent $\left(\mathrm{CaCl}_{2}\right)$ have also shown a negative impact on $\%$ drug release rate at $6 \mathrm{~h}$. However the quadratic responses of both X1 and $\mathrm{X} 2$ shown positive response towards \% drug release at $6 \mathrm{~h}^{[66]}$. Optimization techniques based on factorial design generated mathematical equations using experimental data and appropriate statistical analysis and helped to select best possible model depending upon independent variables $^{[68]}$.

Response surface methodology based on $3^{2}$ factorial design with two independent variables, ratio of polymers (FSM:SA) $\left(\mathrm{X}_{1}\right)$ and concentration of $\mathrm{CaCl}_{2}$ $\left(\% \mathrm{w} / \mathrm{v}, \mathrm{X}_{2}\right)$ were adopted for formulation optimization and their effect on DEE $(\%)$, bead size $(\mu \mathrm{m})$ and $\mathrm{Q}_{6}$ $(\%)$ were summarized in Tables 1 and 3 . The contour and surface response plot for DEE, bead size and Q6 were given in fig. 4. Based upon the responses of observed formulations (F1-F9), factorial design software (Design-Expert 11) proposed specified point prediction values for independent variable (FSM:SA) as $\left(\mathrm{X}_{1}\right)$ and $\mathrm{CaCl}_{2}(\% \mathrm{w} / \mathrm{v})\left(\mathrm{X}_{2}\right)$ as $3.06: 1$ and $7.36 \%$ $\mathrm{w} / \mathrm{v}$, respectively.

In order to validate the equation that describes the influence of independent parameters on \% DEE, BS and Q6 \%, an additional check point experiment was performed (Table 2B). The check point batch of FSM-SA bead (F0) containing 5-FU was formulated using predicted quantities of $\mathrm{X}_{1}$ and $\mathrm{X}_{2}$, and Table 2B summarized predicted and observed values with $\%$ errors. F0 have showed percentage error of $2.14 \%$ for $\% \mathrm{DEE}$ (80.97 and 78.83), $4.76 \%$ for BS (1003.76 and $999.3 \mu \mathrm{m}$ ) and $-2.52 \%$ for $\% \mathrm{Q}_{6}(36.22$ and 38.74 ). From the result analysis, it was found that there was excellent agreement between the measured response and predicted response. The difference between measured and predicted values were not found to be statistically insignificant. Thus, it can be concluded that the polynomial equations fit the data satisfactorily and were valid for predicting the \% DEE, BS and \% Q6 for multiparticulate beads of 5-FU towards colon targeting. Thus, considering the results from $3^{2}$ full factorial design, the batch F0 was selected as the optimized batch $^{[66]}$.

The release data of different formulations including coated and uncoated SA beads was presented in fig. 5A. 
The in vitro release of SA beads (U0) showed $\sim 8 \%$ in $1 \mathrm{~h}$ and $100 \%$ in $6 \mathrm{~h}$ release of 5-FU in simulated gastric fluid, whereas coating of ES100 $(10 \% \mathrm{w} / \mathrm{v})$ to SA beads (C0) showed significantly delayed release as it took $\sim 12 \mathrm{~h}$ to release $100 \%$ drug and only $8 \% 5-\mathrm{FU}$ appeared after $4 \mathrm{~h}$. These findings agreed with those of various earlier investigations ${ }^{[69-71]}$ and signified that neither uncoated, nor the ES100-coated SA beads were able to retard the release of 5-FU in the gastric as well as in colonic region. Moreover, many scientists have incorporated various natural and synthetic polymeric materials/blends to achieve the desired degree of sustainability in terms of release of different drug molecules. FSM containing galactomannans has also been used for mucoadhessive formulations of guar gum, locust bean gum, tara gum, gum Arabic and tragacanth gum $^{[72-75]}$.

5-FU-containing SA/FSM multiparticulate formulation F0 (uncoated SA-FSM beads) optimized from linear and quadratic models of $3^{2}$ factorial designs showed release of $\sim 10 \%$ in $2 \mathrm{~h}, \sim 39 \%$ in $6 \mathrm{~h}$ and $100 \%$ drug in $12 \mathrm{~h}$, which was significantly slower than SA containing beads (U0). This delayed drug release must be due to the increased viscosity of polymeric matrix imparted by FSM. Moreover, Nayak et al. also reported that hydrophilic FSM also binds with water to form viscous gel-structure, which barricades the pores on the surface of polymeric matrix ${ }^{[76]}$. Retardation of drug release from polymer matrix might be the synergistic effect of both viscosity and gel forming properties of FSM, which also corroborated with various earlier findings ${ }^{[48,77-79]}$.

ES100 like coating of SA beads (C0), also extended the release of F0. SA/FSM beads were coated with $5 \%(\mathrm{P} 1), 10 \%(\mathrm{P} 2)$ and $15 \%(\mathrm{P} 3) \mathrm{w} / \mathrm{v}$ of ES100. Coated batch $\mathrm{P}_{3}$ exhibited least $\%$ drug release of $\sim 2 \%$, $11 \%, 46 \%$ and $\sim 85 \%$ in $2,6,12$ and 18 h respectively as compared to batch $\mathrm{P}_{1}(\sim 3,22,58$ and $97 \%)$ and $\mathrm{P}_{2}$ $(\sim 2,16,51$ and $91 \%)$. However, $>75 \%$ of drug was released from the coated beads when $\mathrm{pH}$ was gradually raised above 7.0, as ES100 coating membrane get dissolved and leads to a disturbance of the integrity of film $^{[80]}$. The released profile data corroborated with the findings of Morelli et al. as ES100 coating prolonged the drug release upto $24 \mathrm{~h}$ for the release of yeast cells into the colonic area ${ }^{[81]}$. Similarly Jena et al. has designed ES100 coated Chitosan microspheres which retarded the Capecitabine release upto $24 \mathrm{~h}$ in colonic region ${ }^{[82]}$. FESEM topographic images also evidently supported the release data as methacrylic acid copolymer,
ES100 coated the wrinkles and cracks on bead surface arises due to collapsing of polymeric gel networks. Smooth texture with lesser cracks evident in FESEM topographic examination of coated beads (fig. 3B, D and $\mathrm{F}$ ) significantly restricted the observed porosity and extended the 5-FU release in concentration dependent manner.

The ex vivo permeability of both coated, uncoated beads (F0 and P3) as well as of pure 5-FU conducted for $18 \mathrm{~h}$ using excised goat colonic mucosa in simulated conditions $(0.1 \mathrm{~N} \mathrm{HCl}$ for $0-2 \mathrm{~h}$, phosphate buffer of $\mathrm{pH} 6.8$ for 2-6 h and phosphate buffer of $\mathrm{pH} 7.4$ for 12 h) using Franz diffusion cell and summarized in fig. $5 \mathrm{~B}$. The study revealed that the percent cumulative drug permeability (\% CDP) for 5-FU was significantly lower as compared to the formulated beads (F0 and $\mathrm{P}_{3}$ ) because of its hydrophilicity. Formulated beads ( $\mathrm{F} 0$ and $\mathrm{P}_{3}$ ) showed lower initial permeability of the drug in $\mathrm{pH} 1.2$ and 6.8, must be attributed to slow hydration as well as slow penetration of the simulated fluids into the bead matrix. Moreover, ES100 coating sealed the micro-pores of beads and restricted the permeation of the medium and findings equally supported by the $6 \mathrm{~h}$ permeability statistics (fig. 5B) ${ }^{[83]}$.

In order to explore the effect of intestinal microbial flora and it's enzymatic environment detailed release study was conducted using human fecal slurries, goat caecal content and probiotics medium. In the dissolution medium without microbiota, the release of the ES100 (15\% w/v) coated beads $\mathrm{P}_{3}$ was found to be $10.89 \%$ up to $6 \mathrm{~h}$ as compared to uncoated (F0) $31.74 \%$. Similar observations were recorded with differentreleasemediumincluding human faecal slurries, goat caecal content and probiotics medium up to $18 \mathrm{~h}$ in comparison to dissolution medium without microbiota, which may be due to the bacterial degradation of polysaccharide monomer units of polymeric structure present in the respective media (fig. 5C and D). The drug release pattern was observed in the following order i.e. $4.5 \% \mathrm{w} / \mathrm{v}$ goat caecal $>$ FTM containing probiotic culture $>5 \% \mathrm{w} / \mathrm{v}$ human faecal slurries $>$ FTM in absence of microbiota in $18 \mathrm{~h}$ for both coated and uncoated beads $\left(\mathrm{P}_{3}\right.$ and $\left.\mathrm{F} 0\right)$. In vitro drug release data for $\mathrm{F} 0$ and $\mathrm{P}_{3}$ were subjected to various kinetic models such as zero order, first order, Higuchi's and Korsmeyer-Peppas equation for release data of 6 and $18 \mathrm{~h}$ to determine the mechanism of drug release (Table 4). The mechanism of drug release in first $6 \mathrm{~h}$ (without microbiota at $\mathrm{pH} 1.2$ $(2 \mathrm{~h})$ and $6.8 \mathrm{(4h)}$ for $\mathrm{F} 0$ and $\mathrm{P}_{3}$ followed zero order and first order erosion mechanisms of drug release $(n>0.85)$ 

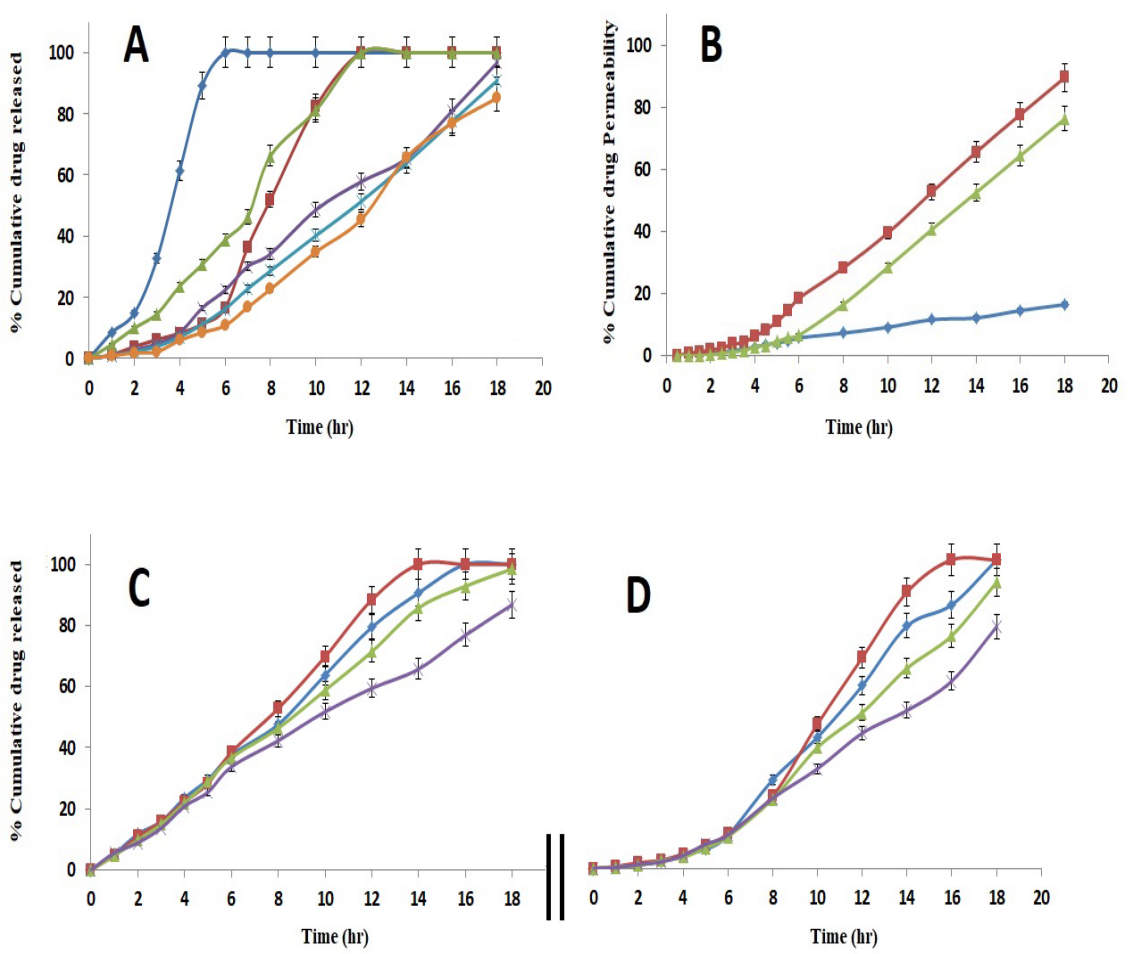

Fig. 5: Drug release profiles

(A) Representing drug release in simulated gastrointestinal conditions (uncoated SA beads (U0), ES100-coated SA beads (C0), uncoated SA-FSM beads (F0), ES100-coated SA-FSM beads P1 (5\%), P2 (10\%) and P3 (15\%)) and B showing drug permeability through goat colon (ex vivo), $\mathrm{C}$ and $\mathrm{D}$ representing drug release profile of formulated beads in simulated gastrointestinal conditions.

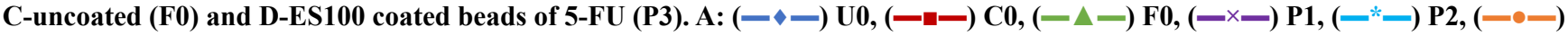

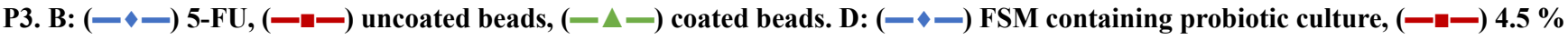
w/v goat caecal contents, $(-\Delta-) 5 \%$ w/v human faecal slurries, $(-\times-)$ FSM in absence of microbiota

\section{TABLE 4. IN VITRO RELEASE KINETICS OF BATCH FO AND P3}

\begin{tabular}{|c|c|c|c|c|c|c|c|c|}
\hline \multirow{2}{*}{ Batch } & \multicolumn{2}{|c|}{ Zero order } & \multicolumn{2}{|c|}{ First order } & \multicolumn{2}{|c|}{ Higuchi } & \multicolumn{2}{|c|}{ Korsmayer-Peppas } \\
\hline & $\mathrm{n}$ & $r^{2}$ & $\mathrm{n}$ & $r^{2}$ & $\mathrm{n}$ & $\mathrm{r}^{2}$ & $\mathrm{n}$ & $r^{2}$ \\
\hline \multicolumn{9}{|c|}{ Dissolution media containing $0.1 \mathrm{~N} \mathrm{HCl}(0-2 \mathrm{~h})$, Phosphate buffer $\mathrm{pH} 6.8$ (2-6 h; without microbiota) } \\
\hline F0 & 6.193 & 0.9941 & 0.1616 & 0.9431 & 25.131 & 0.9714 & 1.0793 & 0.9958 \\
\hline P3 & 1.687 & 0.8915 & 0.2534 & 0.9813 & 6.548 & 0.8430 & 1.6436 & 0.9771 \\
\hline \multicolumn{9}{|c|}{ FTM containing probiotic culture $\left(6^{\text {th }}\right.$ to $\left.18 \mathrm{~h}\right)$} \\
\hline F0 & 5.452 & 0.9357 & 0.0322 & 0.8948 & 39.124 & 0.9596 & 0.9474 & 0.9548 \\
\hline P3 & 7.204 & 0.9886 & 0.0534 & 0.9467 & 51.145 & 0.9922 & 1.5518 & 0.9848 \\
\hline \multicolumn{9}{|c|}{ Dissolution media containing $0.1 \mathrm{~N} \mathrm{HCl}(0-2 \mathrm{~h})$, Phosphate buffer $\mathrm{pH} 6.8$ (2-6 h; without microbiota) } \\
\hline F0 & 6.211 & 0.9872 & 0.1682 & 0.9470 & 25.842 & 0.9564 & 1.1216 & 0.9964 \\
\hline P3 & 1.785 & 0.9129 & 0.2274 & 0.9780 & 6.813 & 0.8580 & 1.4798 & 0.9795 \\
\hline \multicolumn{9}{|c|}{$4.5 \%$ Goat caecal contents $\left(6^{\text {th }}\right.$ to $\left.18 \mathrm{~h}\right)$} \\
\hline F0 & 4.828 & 0.8359 & 0.0272 & 0.8053 & 34.998 & 0.8748 & 0.8149 & 0.8878 \\
\hline P3 & 8.043 & 0.9301 & 0.0607 & 0.8471 & 57.735 & 0.9543 & 1.8025 & 0.9215 \\
\hline \multicolumn{9}{|c|}{ Dissolution media containing $0.1 \mathrm{~N} \mathrm{HCl}(0-2 \mathrm{~h})$, Phosphate buffer pH 6.8 (2-6 h; without microbiota) } \\
\hline F0 & 6.102 & 0.9905 & 0.1728 & 0.9575 & 26.055 & 0.9783 & 1.1465 & 0.9974 \\
\hline P3 & 1.650 & 0.8877 & 0.267 & 0.9795 & 6.447 & 0.8422 & 1.7294 & 0.9725 \\
\hline \multicolumn{9}{|c|}{$5 \%$ human faecal slurries $\left(6^{\text {th }}\right.$ to $\left.18 \mathrm{~h}\right)$} \\
\hline F0 & 5.393 & 0.9773 & 0.033 & 0.9477 & 38.438 & 0.9887 & 0.9596 & 0.9855 \\
\hline P3 & 6.774 & 0.9959 & 0.0576 & 0.9467 & 47.935 & 0.9930 & 1.6723 & 0.9836 \\
\hline \multicolumn{9}{|c|}{ Dissolution media containing $0.1 \mathrm{~N} \mathrm{HCl}(0-2 \mathrm{~h})$, Phosphate buffer pH 6.8 (2-6 h; without microbiota) } \\
\hline F0 & 5.465 & 0.9872 & 0.1562 & 0.9803 & 23.661 & 0.9763 & 1.0147 & 0.9784 \\
\hline P3 & 1.812 & 0.8948 & 0.2868 & 0.9616 & 7.1273 & 0.8573 & 1.8908 & 0.9887 \\
\hline \multicolumn{9}{|c|}{ FTM in absence of microbiota $\left(6^{\text {th }}\right.$ to $\left.18 \mathrm{~h}\right)$} \\
\hline F0 & 4.346 & 0.9936 & 0.0303 & 0.9914 & 30.669 & 0.9852 & 0.8636 & 0.9935 \\
\hline P3 & 5.292 & 0.9841 & 0.051 & 0.9785 & 37.284 & 0.9726 & 1.464 & 0.9934 \\
\hline
\end{tabular}


respectively. Similarly in case of simulated colonic fluids such as FTM containing probiotic culture, $5 \%$ human faecal slurries and FTM in absence of microbiota both the coated and uncoated beads followed zero order super case II transport (erosion) principle of drug release at $6-18 \mathrm{~h}(\mathrm{n}>0.85)$. The mechanisms associated with drug release for uncoated beads (F0) in $4.5 \%$ Goat caecal contents was found to be zero order Anomalous diffusion $(\mathrm{n}<0.85)$ in $6-18 \mathrm{~h}$ whereas for coated beads (P3) the mechanism of drug release was zero order super case II transport (erosion) type ${ }^{[84]}$. The above observation signified that, the polymeric blends of SAFSM are much more efficient to control the drug release in colonic environment.

Colorectal cancer is the third widespread cancer mostly affecting older people. Chemotherapy with 5-FU reduces the chances of cancer progression. 5-FU, has an established chemotherapeutic activity needs to be targeted into colon for target specific local therapy as well as to reduce the dose related side effects. Polynomial equations by statistical evaluation of the results were obtained in order to correlate the independent and dependent variables. Desirability/predictability function was utilized to obtain the optimized batch. Based on the overall desirability factor and design expert software the optimized batch was selected. To achieve site specific drug release, fabricated SA-FSM multiparticulate beads containing 5-FU was coated with Eudragit S100 as coating polymer. The SA-FSM beads loaded with 5-FU were formulated using ionotropic gelation technique which was supposed to get degraded by the colonic bacteria. The proposed prediction values for the optimized batch containing (FSM:SA) as $\left(\mathrm{X}_{1}\right)$ and $\mathrm{CaCl}_{2}(\% \mathrm{w} / \mathrm{v})\left(\mathrm{X}_{2}\right)$ as $(3.06: 1)$ and $(7.36 \% \mathrm{w} / \mathrm{v})$, respectively. The formulation was optimized using $3^{2}$ full factorial design. The $\%$ in vitro drug release study was performed by changeover media in which initially $0.1 \mathrm{~N} \mathrm{HCl}$ was used followed by phosphate buffer pH 6.8 and finally phosphate buffer $\mathrm{pH} 7.4$ wherein formulation exhibited sustained release effect till $18 \mathrm{~h}$. The ex vivo permeability study was performed in goat colon and different kinetic models were applied to check the release mechanisms of beads, which indicated that coated beads followed zero order super case II transport (erosion) mechanism. Thus, all the results obtained while development of the dosage form were as per the desired set of the objectives. Therefore, the coated beads can be a good candidate for site specific delivery of 5-FU to colon by decreasing the gastric irritation, reducing dose frequency and by improving patient compliance for the treatment of colon cancer.
Though, the in vivo study should be performed using suitable animal model to demonstrate the enhancement in bioavailability and site specific action of formulation. Therefore, this kind of formulation targeting 5-FU to the colon can be effective due to local action to delay or prevent development of colon cancer.

\section{Conflict of interest:}

The authors of the article do not have any conflict of interest.

\section{REFERENCES}

1. Davis SS. Assessment of gastrointestinal transit and drug absorption. In: Rescott LF, Nimmo WS, editors. Novel Drug Delivery and Its Therapeutic Application. Chichester, UK: John Wiley; 1990. p. 89-101.

2. Chourasia MK, Jain SK. Pharmaceutical approaches to colon targeted drug delivery systems. J Pharm Pharm Sci 2003;6(1):33-66.

3. Chaurasia M, Chourasia MK, Jain NK. Cross-linked guar gum microspheres: a viable approach for improved delivery of anticancer drugs for the treatment of colorectal cancer. AAPS Pharm Sci Tech 2006;7(3):E1-E9.

4. Shimono N, Takatori T, Masumi T. Chitosan dispersed system for colon-specific drug delivery. Int J Pharm 2002;245(12):45-54.

5. Tozaki H, Komoike J, Tada C. Chitosan capsules for colonspecific drug delivery: Improvement of insulin absorption from the rat colon. J Pharm Sci 1997;86(9):1016-21.

6. Jain A, Gupta Y, Jain SK. Potential of calcium pectinate beads for target specific drug release to colon. J Drug Target 2007;15(4):285-94.

7. Rubinstein A. Microbially controlled drug delivery to the colon. Biopharm Drug Dispos 1990;11(6):465-75.

8. Ashford M, Fell JT, Attwood D, Sharma H, Woodhead P. An in vivo investigation into the suitability of $\mathrm{pH}$-dependent polymers for colonic targeting. Int J Pharm 1993;95(1-3):19399.

9. Patil JS, Kamalapur MV, Marapur SC, Kadam DV. Ionotropic gelation and polyelectrolyte complexation: the novel techniques to design hydrogel particulate sustained, modulated drug delivery system: A review. Digest J Nanomat Biostruct 2010;5(1):241-48.

10. Racovita S, Vasilu S, Popa M, Luca C. Polysaccharides based micro- and nanoparticles obtained by ionic gelation and their applications as drug delivery systems. Rev Roumaine De Chimie 2009;54(9):709-18.

11. Tummala S, Kumar M.N.S, Prakash A. Formulation and characterization of 5-Fluorouracil enteric coated nanoparticles for sustained and localized release in treating colorectal cancer. Saudi Pharm J 2015;23(3):308-14.

12. Patel YL, Sher P, Pawar AP. The effect of drug concentration and curing time on processing and properties of calcium alginate beads containing metronidazole by response surface methodology. AAPS Pharm Sci Tech 2006;7(4):E1-E7.

13. Shilpa A, Agarwal SS, Rao AR. Controlled delivery of drug from alginate matrix. J Macromol Sci Polym Rev 2003;43(2):187-21.

14. Yoo SH, Song YB, Chang PS, Lee HG. Microencapsulation of alpha-tocopherol using sodium alginate and its controlled 
release properties. Int J Biol Macromol 2006;38(1):25-30.

15. Llanes F, Ryan DH, Marchessault RH. Magnetic nanostructured composites using alginates of different $\mathrm{M} / \mathrm{G}$ ratios as polymeric matrix. Int J Biol Macromol 2000;27(1):35-40.

16. Kroll E, Winnik FM, Ziolo RF. In situ preparation of nanocrystalline $\left(\gamma-\mathrm{Fe}_{2} \mathrm{O}_{3}\right.$ in iron (II) crosslinked alginate gels. Chem Mater 1996;8(8):1594-96.

17. Pal D, Nayak AK. Development, optimization, and antidiabetic activity of gliclazide-loaded alginate-methyl cellulose mucoadhesive microcapsules. AAPS Pharm Sci Tech 2011;12(4):1431-41.

18. Prajapati SK, Tripathi P, Ubaidulla U, Anand V. Design and development of gliclazide mucoadhesive microcapsules: In vitro and in vivo evaluation. AAPS Pharm Sci Tech 2008;9(1):224-230.

19. Nayak AK, Khatua S, Hasanin MS, Sen KK. Development of alginate-PVP K30 microbeads for controlled Diclofenac sodium delivery using central composite design. DARU J Pharm Sci 2011;19(5):356-66.

20. Nayak AK, Pal D. Development of $\mathrm{pH}$-sensitive tamarind seed polysaccharide alginate composite beads for controlled Diclofenac sodium delivery using response surface methodology. Int J Biol Macromol 2011;49(4):784-93.

21. Pal D, Nayak AK. Novel tamarind seed polysaccharide-alginate mucoadhesive microspheres for oral gliclazide delivery. Drug Deliv 2012;19(3):123-31.

22. Nayak AK, Hasnain MS, Beg S, Alam MI. Mucoadhesive beads of gliclazide: Design, development, and evaluation. Sci Asia 2010;36(4):319-25.

23. Sachan SK, Bhattacharya A. Modeling and characterization of drug release from glutinous rice starch based hydrogel beads for controlled drug delivery. Int J Heal Res 2009;2(1):293-99.

24. Maurya DP, Sultana Y, Aqil M, Kumar D, Chuttani K, Ali A, et al. Formulation and optimization of alkaline extracted ispaghula husk microparticles of isoniazid in vitro and in vivo assessment. J Microencap 2011;28(6):472-82.

25. Dutta R, Bandyopadhyay AK. Development of a new nasal drug delivery system of diazepam with natural mucoadhesive agent from Trigonella foenumgraecum L. J Sci Ind Res 2005;64(12):973-77.

26. Sabale V, Patel V, Paranjape A, Sabale P. Isolation of fenugreek seed mucilage and its comparative evaluation as a binding agent with standard binder. Int Res J Pharm 2009;1(4):56-62.

27. Kumar R, Patil S, Patil MB, Patil SR, Paschapur MS. Isolation and evaluation of disintegrant properties of fenugreek seed mucilage. Int J Pharm Tech Res 2009;1(4):982-96.

28. Kumar GS, Shetty AK, Sambaiah K, Salimath PV. Antidiabetic property of fenugreek seed mucilage and spent turmeric in streptozotocin-induced diabetic rats. Nutr Res 2005;25(11):1021-28.

29. Jiang JX, Zhu LW, Zhang WM, Sun RC. Characterization of Galactomannan Gum from Fenugreek (Trigonella foenumgraecum) Seeds and Its Rheological Properties. Int J Polym Mat Polym Biomat 2007;56(12):1145-54.

30. Verma S, Bansal J, Kumar N, Malviya R, Sharma PK. Isolation and Characterization Studies of Mucilage Obtained from Trigonella foenum Greacum L. Seed and Tamarindus Indica Polysaccharide as a Pharmaceutical Excipient. J Drug Deliv Ther 2014;4(3):106-09.

31. Ahmad MZ, Akhter S, Anwar M, Ahmad FJ. Assam Bora Rice Starch Based Biocompatible Mucoadhesive Microsphere for Targeted Delivery of 5-Fluorouracil in Colorectal Cancer. Mol Pharm 2012;9(11):2986-94.
32. Bushra N, Nazar MR, Muhammad H, Saira N, Ghulam A, Samina A, et al. Pharmacokinetic Studies of 5-Fluorouracil in Rabbit Plasma. Acta Pol Pharma Drug Res 2017;74:1573-78.

33. Yassin AEB, Anwer MDK, Mowafy HA, El-Bagory IM, Bayomi MA, Alsarra IA. Optimization of 5-flurouracil solidlipid nanoparticles: a preliminary study to treat colon cancer. Int J Med Sci 2010;7(6):398-08.

34. Inamdar M, Abhang $\mathrm{P}$, Momin M. Isolation And Evaluation of Fenugreek, Flaxseed Mucilages and Its use as a pharmaceutical Binder. Int J Pharm Tech 2012;4(3):4766-77.

35. Odeku OA, Okunlola A, Lamprecht A. Formulation and In vitro Evaluation of Natural Gum-Based Microbeads for Delivery of Ibuprofen. Trop J Pharm Res 2014;13(10):1577-83.

36. Larosa C, Salerno M, Lima JS, Meri RM, Silva MF, Carvalho $\mathrm{LB}$, et al. Characterisation of bare and tannase-loaded calcium alginate beads by microscopic, thermogravimetric, FTIR and XRD analyses. Int J Biol Macromol 2018;115:900-06.

37. Attia AK, Ibrahim MM, El-Ries MAN. Thermal Analysis of Some Antidiabetic Pharmaceutical Compounds. Adv Pharm Bull 2013;3(2):419-24.

38. Samar MA, Ahmed A, Aboelwafa RMK, Omaima NEG. Utilization of ionotropic gelation technique for bioavailability enhancement of cinnarizine: in-vitro optimization and invivo performance in human. Drug Deliv 2016;23(8):2736-46.

39. Hussain A, Singh SK, Verma PRP, Singh N, Ahmad FJ. Experimental design-based optimization of lipid nanocarrier as delivery system against Mycobacterium species: in vitro and in vivo evaluation. Pharm Dev Technol 2017;22(7):910-27.

40. Ramteke KH, Jadhav VB, Kulkarni NS, Kharat AR, Diwate SB. Preparation, Evaluation and Optimization of Multiparticulate System of Mebendazole for Colon Targeted Drug Delivery by Using Natural Polysaccharides. Adv Pharm Bull 2015;5(3):361-71.

41. Jain A, Jain SK. Formulation and optimization of temozolomide nanoparticles by 3 factor 2 level factorial design. Biomatter 2013;3(2):1-13.

42. Patel N, Desai J, Kumar P, Thakkar HP. Development and In-Vitro Characterization of Capecitabine Loaded AlginatePectinate Chitosan Beads for Colon Targeting. J Macromol Sci Part B 2015;54(1):1-48.

43. Narade S, Pore Y. Optimization of ex vivo permeability characteristics of berberine in presence of quercetin using $3^{2}$ full factorial design. J Appl Pharm Sci 2019;9(1):073-082.

44. Maestrelli F, Cirri M, Corti G, Mennini N, Mura P. Development of enteric-coated calcium pectinate microspheres intended for colonic drug delivery. Eur J Pharm Biopharm 2008;69(2):50818.

45. Sareen R, Jain N, Rajkumari A, Dhar KL. pH triggered delivery of curcumin from Eudragit-coated chitosan microspheres for inflammatory bowel disease: characterization and pharmacodynamic evaluation. Drug Deliv 2016;23(1):55-62.

46. Patel N, Lalwani D, Gollmer S, Injeti E, Sari Y, Nesamony J. Development and evaluation of a calcium alginate based oral ceftriaxone sodium formulation. Prog Biomater 2016;5(2):117-33.

47. Costa P, Sousa LJM. Modeling and comparison of dissolution profiles. Eur J Pharm Sci 2001;13(2):123-33.

48. Nokhodchi A, Hossein N, Khodaparast A, Sorkh-Shahan T, Hadi V, Ford JL. An In Vitro Evaluation of Fenugreek Mucilage as a Potential Excipient for Oral Controlled-Release Matrix Tablet. Drug Dev Ind Pharm 2008;34(3):323-29.

49. Yang L, Chu JS, Fix JA. Colon-specific drug delivery: new approaches and in vitro/in vivo evaluation. Int $\mathrm{J}$ Pharm 
2002;235(1-2):1-15.

50. Yadav AK, Sadora M, Singh SK, Gulati M, Maharishi P, Sharma A, et al. Novel biorelevent dissolution medium as a prognostic tool for polysaccharide based colon targeted drug delivery system. J Adv Pharm Technol Res 2017;8(4):150-55.

51. Li P, Dai YN, Zhang JP, Wang AQ, Wei Q. Chitosan-Alginate Nanoparticles as a Novel Drug Delivery System for Nifedipine. Int J Biomed Sci 2008;4(3):221-28.

52. Nayak AK, Pal D. Trigonella foenum-graecum L. seed mucilage-gellan mucoadhesive beads for controlled release of metformin HCl. Carbohydrate Polym 2014;107:31-40.

53. Soares JP, Santos JE, Chierice GO, Cavalheiro ETG. Thermal behaviour of alginic acid and its sodium salt. Ecl Quím São Paulo 2004;29(2):53-56.

54. Miguel A, Cerqueira AC, Pinheiro LMP, António AV. Amphiphilic Modified Galactomannan as a Novel Potential Carrier for Hydrophobic Compounds. Front Sustain Food Syst 2019;3:1-8.

55. Lavudi HN, Kottapalli S, Goycoolea FM. Extraction and physicochemical characterization of galactomannans from Dichrostachys cinerea seeds. Food Hydrocol 2018;82:451-56.

56. Joana TM, Miguel AC, Ana IB, Ana CP, Bartolomeu WSS, António AV. Synergistic effects between k-carrageenan and locust bean gum on physicochemical properties of edible films made thereof. Food Hydrocolloid 2012;29:280-89.

57. Joana S, Maricato E, Fernando MN, Domingues MR, Manuel AC. Thermal stability of spent coffee ground polysaccharides: Galactomannans and arabinogalactans. Carbohydrate Polym 2014;101:256-64.

58. Miguel AC, Bartolomeu WSS, Joana S, José AT, Domingues MRM, Manuel AC, et al. Structural and thermal characterization of galactomannans from non-conventional sources. Carbohydrate Polym 2011;83:179-85.

59. Rashid F, Hussain S, Ahmed Z. Extraction purification and characterization of galactomannan from fenugreek for industrial utilization. Carbohydrate Polym 2018;180:88-95.

60. Jadwiga OC, Magdalena GD. Effect of ionic crosslinking on the water state in hydrogel chitosan membranes. Carbohydrate Polym 2009;77:590-98.

61. Patel N, Lalwani D, Gollmer S, Injeti E, Sari Y, Nesamony J. Development and evaluation of a calcium alginate based oral ceftriaxone sodium formulation. Prog Biomater 2016;5(2):11733.

62. Nithitanakool S, Pithayanukul P, Bourgeois S, Fessi H, Bavovada R. The Development, Physicochemical Characterisation and in Vitro Drug Release Studies of Pectinate Gel Beads Containing Thai Mango Seed Kernel Extract. Molecule 2013;18(6):6504-20.

63. Sriamornsak $\mathrm{P}$, Thirawong N. Use of back-scattered electron imaging as a tool for examining matrix structure of calcium pectinate. Int J Pharm 2003;267(1-2):151-56.

64. Mandal S, Kumar SS, Krishnamoorthy B, Basu SK. Development and evaluation of calcium alginate beads prepared by sequential and simultaneous methods. Braz J Pharm Sci 2010;46(4):785-93.

65. Ramteke KH, Jadhav VB, Nilesh Kulkarni S, Kharat AR, Diwate SB. Preparation, Evaluation and Optimization of Multiparticulate System of Mebendazole for Colon Targeted Drug Delivery by Using Natural Polysaccharides. Adv Pharm Bull 2015;5(3):361-71.

66. Paradkar M, Amin J. Formulation development and evaluation of colon targeted delayed release Methotrexate pellets for the treatment of colonic carcinoma. Braz J Pharm Sci 2018;54(4):1-12.

67. Tavakol M, Farahani EV, Najafabadi SH. The effect of polymer and $\mathrm{CaCl} 2$ concentrations on the sulfasalazine release from alginate-N, O-carboxymethyl chitosan beads. Prog Biomat 2013;2(1):1-8.

68. Kadam VD, Gattani SG. Development of colon targeted multiparticulate pulsatile drug delivery system for treating nocturnal asthma. Drug Deliv 2010;17(5):343-51.

69. Chawla A, Sharma P, Pawa P. Eudragit S-100 coated sodium alginate microspheres of naproxen sodium: Formulation, optimization and in vitro evaluation. Acta Pharm 2012;62(4):529-45.

70. Ansari F, Pourjafar H, Jodat V, Javad S, Ataei A. Effect of Eudragit S100 nanoparticles and alginate chitosan encapsulation on the viability of Lactobacillus acidophilus and Lactobacillus rhamnosus. AMB Exp 2017;7; 1-8.

71. Kumar A, Dwivedi H, Kymonil KM Pandey AK. Targeted Delivery and In-vitro Evaluation of Norfloxacin and Tinidazole for Colonic Ailments. Drug Deliv Lett 2018;8:106-15.

72. Rajpurohit H, Sharma P, Sharma S, Bhandari A. Polymers for Colon Targeted Drug Delivery. Ind J Pharm Sci 2010;72(6):689-96.

73. Chourasia MK, Jain SK. Polysaccharides for Colon Targeted Drug Delivery. Drug Deliv 2004;11(2):129-48.

74. Carien E, Beneke AMV, Josias HH. Polymeric Plant-derived Excipients in Drug Deliv. Molecule 2009;14(7):2602-20.

75. Joana LMS, Tania MBB. Pharmaceutical use of galactomannans. Quim Nova 2011;34(2):292-99.

76. Nayak AK, Pal DK, Pradhan J, Hasnain MS. Fenugreek seed mucilage-alginate mucoadhesive beads of metformin $\mathrm{HCl}$ : Design, optimization and evaluation. Int $\mathrm{J}$ Biol Macromol 2013;54:144-54.

77. Kumar RV, Sinha VR. A Novel Synergistic GalactomannanBased Unit Dosage Form for Sustained Release of Acarbose. AAPS Pharm Sci Tech 2012;13(1):262-75.

78. Shukla AK, Bishnoi RS, Kumar M, Jain CP. Isolation and characterization of natural and modified seed gum. Asian J Pharm Pharmacol 2019;5(2):409-18.

79. George B, Suchithra TV. Plant-derived bioadhesives for wound dressing and drug delivery system. Fitoterapia 2019;137:1-14.

80. Ramasamy T, Ruttala HB, Shanmugam S, Umadev SK. Eudragit-coated Aceclofenac-loaded pectin microspheres in chronopharmacological treatment of rheumatoid arthritis. Drug Deliv 2013;20(2):65-77.

81. Morelli S, Holdich R, Dragosavac M. Microparticles for cell encapsulation and colonic delivery produced by membrane emulsification. J Memb Sci 2017;524:377-88.

82. Jena GK, Sahoo SK, Patra CN, Panigrahi KC, Sahu S, Dixit PK. Design, Optimization, and Evaluation of Capecitabineloaded Chitosan Microspheres for Colon Targeting. Asian J Pharm 2017;11(3):S592-02.

83. Pattnaik S, Swain K, Rao JV, Varun T, Prusty KB, Subudhi SK. Polymer co-processing of ibuprofen through compaction for improved oral absorption. RSC Adv 2015;5:74720-25.

84. Gao Y, Zuo J, Bou-Chacra N, Pinto TJA, Clas SD, Walker $\mathrm{RB}$, et al. In Vitro Release Kinetics of Antituberculosis Drugs from Nanoparticles Assessed Using a Modified Dissolution Apparatus. Bio Med Res Int 2013;2013:136590. 